\title{
Immunochemistry of Group F Streptococci; Isolation of Group Specific Oligosaccharides
}

\author{
By M. F. MICHEL AND J. M. N. WILLERS \\ Laboratory of Microbiology, Catharijnesingel 59, State University, Utrecht, \\ The Netherlands
}

(Received 25 May 1964)

SUMMARY

\begin{abstract}
A disaccharide was isolated by partial hydrolysis from the group specific polysaccharide of a streptococcus strain carrying the group antigen $\mathrm{F}$. The most probable structure of the substance is 3-0- $\beta$-D-glucopyranosyl- $N$-acetyl-D-galactosamine. The disaccharide was $\mathbf{3 0 0}$ times more active than cellobiose in the inhibition of the F/anti-F system. This denotes that it is a component of the determinant group of the group antigen. Two other serologically active oligosaccharides were isolated from the hydrolysate. Though their structure was not fully elucidated, evidence was obtained that a tetrasaccharide consisting of two molecules of the disaccharide is an important part of a determinant group of the $\mathbf{F}$ antigen.
\end{abstract}

\section{INTRODUCTION}

In previous communications it was reported (Ottens, 1961; Ottens \& Winkler, 1962) that in group F streptococci one can distinguish between strains carrying only group antigen $\mathbf{F}$ and strains which carry one of five additional type antigens. Both the group and the type antigens are located in the cell wall and are of carbohydrate nature.

A study of the chemical composition of these antigens (Willers, Michel, Sijsma \& Winkler, 1964) showed that the main components of the group antigen are glucose, galactosamine and rhamnose. The same authors showed that the precipitation of the $F$ antigen with anti-F serum was inhibited with increasing activity by: glucose, $\beta$-methyl-glucoside, gentiobiose and cellobiose.

From this it was concluded that a glucose molecule glycosidically linked in the $\beta$-configuration constitutes an important feature of the determinant group of the group $\mathbf{F}$ polysaccharide. The present communication describes the isolation of three oligosaccharides from partial hydrolysates of the group F polysaccharide. All these oligosaccharides were much more inhibitory than cellobiose in the F/anti-F system. The structure of one of the oligosaccharides, a disaccharide, was fully elucidated. A related disaccharide isolated from a hydrolysate of cell walls was also used for analytical work.

\section{METHODS}

Preparation of cell wall hydrolysate. The strain used was I 57 (Ottens \& Winkler, 1962). Ten l. of Todd-Hewitt broth enriched with $0.2 \%$ glucose were inoculated and incubated for $36 \mathrm{hr}$. at $37^{\circ}$. The organisms were harvested in a continuous flow 
centrifuge. Cell walls were prepared as described earlier (Michel \& Gooder, 1962). $300 \mathrm{mg}$. dry cell walls were hydrolysed for $2 \mathrm{hr}$ at $100^{\circ}$ with $2 \mathrm{~N}-\mathrm{H}_{2} \mathrm{SO}_{4}$ and the hydrolysate neutralized with saturated $\mathrm{Ba}(\mathbf{O H})_{2}$.

Preparation of the group specific polysaccharide. The same strain was grown in 80 l. of Todd-Hewitt broth with $\mathbf{0 . 2} \%$ glucose; after harvesting the cocci were washed once with water and recentrifuged at high speed $(36,000 \mathrm{~g})$. The group polysaccharide was obtained by formamide extraction according to Fuller (1938). The amount of formamide used was $520 \mathrm{ml}$. Proteins were precipitated from the extract by the addition of acid ethanol (1.3 1.); after centrifugation the crude polysaccharide was precipitated from the supernatant fluid by the addition of acetone $(2 \cdot 6 \mathrm{l}$.). This material which was partially soluble in distilled water was dialysed for $48 \mathrm{hr}$ against several changes of distilled water. The insoluble material was then discarded by centrifugation. The total volume at this stage was $1700 \mathrm{ml}$.

Partial hydrolysis and chromatographic methods. Controlled hydrolysis was performed with polystyrene sulphonic acid (PSS; Painter, 1960); $1600 \mathrm{ml}$. formamide extract were treated in four $400 \mathrm{ml}$. portions. Each portion was brought at $\mathrm{pH} \mathbf{2 \cdot 3}$ with PSS (about $800 \mathrm{mg}$. of PSS with a monosulphonation degree of $7 \cdot 3$ ) and after addition of Dowex $50 \mathrm{H}^{+}\left(5 \mathrm{~g}\right.$. wet weight) heated in a dialysis bag at $60^{\circ}, 70^{\circ}$ and $86^{\circ}$ in three successive periods of $4 \mathrm{hr}$. During the heating continuous dialysis against distilled water $(1 \mathrm{l} . / \mathrm{hr})$ was applied. The volume of the dialysate was reduced to 11 . by evaporation in vacuo.

The unhydrolysed polysaccharide was recovered by precipitation of PSS by the calculated amount of cetyl trimethylammonium hydroxide (Painter, 1960). The latter substance was prepared from cetyl trimethylammonium bromide by passage through a Dowex $1 \mathbf{O H}^{-}$column.

Separation of monosaccharides and oligosaccharides was performed on a charcoal column prepared as described by Schiffmann, Howe \& Kabat (1958). The dialysate obtained after partial hydrolysis was slowly adsorbed on a column $(50 \times 2 \mathrm{~cm}$.) containing $36 \mathrm{~g}$. Darco G $60+36 \mathrm{~g}$. Celite 535. Elution was started with water $(2.5$ l.) until no more reducing sugars could be detected in the eluate. After further elution with $2 \%(\mathrm{v} / \mathrm{v})$ ethanol (1 1.) an ethanol gradient using a two-flask system (Block \& Ling, 1954) was imposed. The ethanol gradient range was from $2 \%(v / v)$ to $22 \%(\mathrm{v} / \mathrm{v})$, in a total volume of $7.5 \mathrm{l}$.

Further separation of the sugars in the pooled fractions containing reducing sugars was obtained by paper chromatography on Whatman no. 3 MM paper. After elution from the paper the individual sugars were adsorbed on small Darco G $60+$ Celite 535 colums and eluted with water and then with ethanol $20 \%(\mathrm{v} / \mathrm{v})$.

Quantitative analysis of the sugar composition of the formamide extract either untreated or treated with PSS was carried out as described in a previous paper (Willers et al. 1964). No attempt was made to separate glucosamine and galactosamine as it had been shown that the glucosamine content of the group antigen was very low.

For paper chromatography the following solvents were used : solvent $A, n$-butanol + acetic acid + water $(60+10+20$, by vol.); solvent $B, 2,4-2,5$ lutidine + water $(65+35$ by vol.). Alkaline silver nitrate reagent was used to detect reducing sugars (Trevelyan, Procter \& Harrison, 1950); ninhydrin reagent for amino groups (Consden \& Gordon, 1948); Elson-Morgan reagent for amino sugars (Partridge, 1948) and Morgan-Elson reagent for $\mathrm{N}$-acetylhexosamines (Salton, 1959). 
Analytical methods. Glucose was determined with the glucose oxidase reaction (Hugett \& Nixon, 1957) and hexosamines by the method of Rondle \& Morgan (1955). Both methods were used in micromodification $(2-6 \mu \mathrm{g}$.) when necessary. $\mathrm{N}$-acetylgalactosamine was determined according to Reissig, Strominger \& Leloir (1956), rhamnose as described by Gibbons (1955), total sugar with phenol + sulphuric acid (Dubois, Gilles, Hamilton, Rebers \& Smith, 1956) with glucose as the standard. Ethanol was determined with Anstie's reagent (Kabat \& Mayer, 1961).

$N$-acetylation. $N$-acetylation was performed under the conditions recommended by Crumpton (1959).

Borohydride reduction. The sugar sequence of the unknown sugars was analysed by complete hydrolysis $\left(4 \mathrm{~N}-\mathrm{HCl}\right.$ for $3 \mathrm{hr}$ at $\left.100^{\circ}\right)$ before and after borohydride reduction. Reduction was carried out as follows: to about $150 \mu \mathrm{g}$. of unknown sugar in $0.1 \mathrm{ml}$. water an equal volume of sodium borohydride in water $(20 \mathrm{mg} . / \mathrm{ml}$.) was added. After standing overnight at room temperature, Dowex $50 \mathrm{H}^{+}$was added to the solution until no more hydrogen escaped. After destruction of the last traces of $\mathrm{NaBH}_{4}$ by the addition of a further small amount of Dowex $50 \mathbf{H}^{+}$, the resin was filtered off, the filtrate evaporated to dryness and boric acid volatilized by six further evaporations in the presence of small amounts of methanol.

Periodate oxidation. The amount of periodate consumed by the disaccharide (435 $\mu \mathrm{g}$.) was determined by the spectrophotometric procedure described by Kabat \& Mayer (1961). Formaldehyde liberated was estimated in the same sample with chromotropic acid (MacFadyen, 1945). The method was standardized by periodate oxidation of serine. The yield of formic acid during oxidation was estimated by the manometric method of Perlin (1954).

Enzyme sensitivity. The effect of $\beta$-glucosidase (Light's) on the disaccharide and on cellobiose and laminaribiose (which functioned as controls) was tested under the following conditions. $0 \cdot 1-1 \mathrm{mg}$. of sugar in $0.2 \mathrm{ml}$. water was incubated for $2 \mathrm{hr}$ at $37^{\circ}$ with $0.4 \mathrm{ml} .0 .2 \mathrm{M}$-acetate buffer $(\mathrm{pH} \mathrm{5.5})$ and $0.2 \mathrm{ml}$. water with or without glucosidase (1 mg.). Glucose was estimated with the glucose oxidase reagent on pairs of appropriate samples.

Serological methods. Inhibition reactions of the quantitative precipitation were carried out as described (Willers et al. 1964). For a comparison of the antigenicity of the group specific polysaccharide with the material remaining unhydrolysed after partial hydrolysis, quantitative precipitations of both were performed with an anti-F serum in the same dilution.

\section{RESULTS}

Isolation and characterization of an oligosaccharide from cell walls. It was pointed out previously (Willers et al. 1964) that on qualitative analysis of group and type antigens the chromatograms showed one or more unidentified reducing-sugar spots. The strongest spot (compound A) was found only in hydrolysates derived from antigens containing the group antigen but was absent from those derived from type antigens.

A cell wall hydrolysate (from $300 \mathrm{mg}$. cell walls) was placed on a Dowex $50 \mathrm{H}^{+}$ column and monosaccharides were eluted with water. By further elution with $\mathbf{0 . 3 3} \mathrm{N}-\mathrm{HCl}$ on a fraction collector (Gardell, 1953) three Elson-Morgan positive 
fractions were obtained. The fraction which came off in the first $30 \mathrm{ml}$., i.e. definitely earlier than glucosamine and galactosamine (Crumpton, 1959), was further purified by paper chromatography (Whatman no. 1) and eluted from the paper after location on the margin. About $3 \mathrm{mg}$. of substance was obtained. The substance had an $\boldsymbol{R}_{g}$ in solvent $\mathbf{A}$ of $\mathbf{0 . 3 8}$, and in solvent $\mathbf{B}$ of $\mathbf{0 . 6 5}$. As these figures correspond exactly with $\boldsymbol{R}_{\boldsymbol{g}}$ values of compound $\mathrm{A}$, it was concluded that compound $\mathrm{A}$ had been isolated.

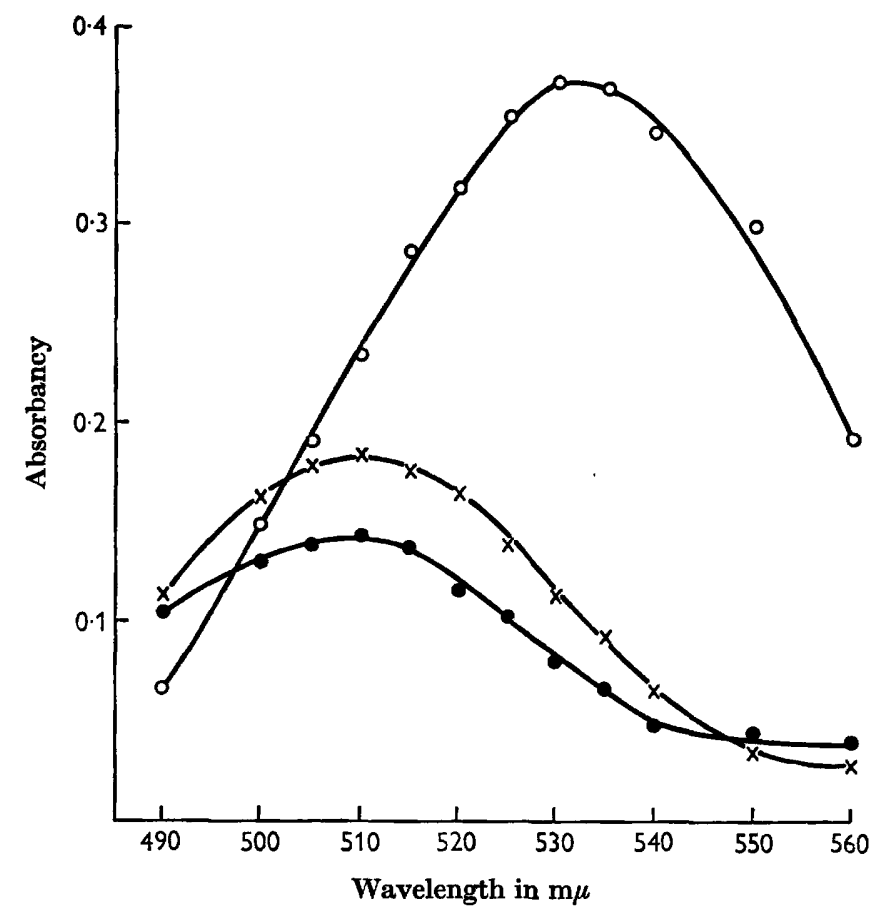

Fig. 1. Spectrum of the Elson-Morgan chromogens of glucosamine-HCl (O), compound A $(x)$ and muramic acid (O). Compound $A$ was isolated from a cell-wall hydrolysate of a group $\mathbf{F}$ streptococcus strain.

Compound A reacted positively with alkaline silver nitrate, with ninhydrin and with Elson-Morgan sprays; but not with the Morgan-Elson reagent. On complete hydrolysis $\left(4 \mathrm{~N}-\mathrm{HCl}\right.$ for $3 \mathrm{hr}$ at $100^{\circ}$ ) and chromatography the substance gave two spots, glucose and galactosamine, of about equal intensity. It was therefore thought at this stage that compound $\mathbf{A}$ was an oligosaccharide, probably a disaccharide, composed of these two sugars.

To obtain information on the type of linkage between the two sugars the spectra of the Elson-Morgan chromogens given by compound A, glucosamine and muramic acid were compared. From the results shown in Fig. 1 it appears that the former two substances gave a maximum at $510 \mathrm{~m} \mu$, whereas the maximum of the latter substance was situated at $530 \mathrm{~m} \mu$. Assuming that compound A is a disaccharide with a glycosidically linked glucose molecule, it was inferred from these data that the galactosamine molecule was substituted at $\mathrm{C}_{3}$.

Confirmation of this structure was obtained by the results of periodate oxidation. 
Compound A consumed 2 mole/mole periodate in the first hour and a total of 4.2 mole in $18 \mathrm{hr}$ (theoretical, 4 mole). After $22 \mathrm{hr}$ the formaldehyde liberated from the sample was 0.9 mole/mole (theoretical, 1 mole). The maximum formic acid production (1.7 mole/mole; theoretical, 2 mole) was obtained after $4 \mathrm{hr}$.

\section{Table 1. Chemical composition and precipitation of group $\boldsymbol{F}$ antigen before and after controlled hydrolysis}

$\begin{array}{lcc}\text { Untreated } & \begin{array}{c}\text { Treated and } \\ \text { dialysed } \\ \text { (mg.) }\end{array} & \begin{array}{c}\text { (mg.) } \\ \text { Glucose }\end{array} \\ \text { Hexosamines } & 135 & 100 \\ \text { Rhamnose } & 300 & 333 \\ & 910 & 488 \\ \text { Ratio of precipitates } & 1345 & 1\end{array}$

The precipitation of the group specific polysaccharide and the material remaining unhydrolysed after controlled hydrolysis was assessed quantitatively with an anti-F serum in the same dilution.

Isolation of three oligosaccharides by partial hydrolysis of the formamide extract. For the production of a larger amount of compound A, partial hydrolysis by PSS was chosen since it has been reported that this method increases the yield of oligosaccharides and also because de-acetylation is prevented (Painter \& Morgan, 1961) making the products directly suitable for serological use.

The effect of mild hydrolysis on the chemical composition and the antigenicity of the group polysaccharide is shown in Table 1. From the analysis of the sugar composition it appears that on hydrolysis a uniform decrease of all the components took place to about one-third of their initial values. This decrease was reflected at the serologically as the hydrolysed material formed only one-third of the precipitate obtained by a comparable amount of the original antigen. This indicates in fact that the serological activity of the polysaccharide was not affected by hydrolysis. Gradient elution of the charcoal column by ethanol produced one large peak which started at $4 \%$ ethanol. The peak contained a shoulder in its descending part starting at $5 \%$ ethanol. On purification of the complete fraction on Whatman no. 3 MM with solvent $\mathbf{A}$, good separation was obtained. Besides a small amount of glucose, one major spot termed compound $\mathbf{A}_{1}$ was detected with the alkaline silver nitrate spray. In addition, two weakly coloured spots with a much lower $\boldsymbol{R}_{g}$ value could be seen (compound $\mathrm{A}_{2}$ and $\mathrm{A}_{3}$ ).

Structure of compound $A_{1}$. The location of compound $A_{1}$ on Whatman no. 1 paper was $R_{g}$, solvent A, 0.59, solvent B, 1.0. The compound A described earlier was now $N$-acetylated. This acetylated compound had the following location: $R_{\mathrm{g}}$, solvent $A$, $0 \cdot 57$, solvent $B, 1 \cdot 0$. From this it was concluded that compound $A_{1}$ was the $N$ acetylated form of compound $A$. When investigated further, compound $A_{1}$ had the following characteristics. It had $\alpha_{\mathrm{D}}^{20}+20^{\circ}$ in water. The amount of colour produced by compound $A_{1}$ in the Morgan-Elson reaction was $160 \%$ of that obtained from an equimolar concentration of $\mathrm{N}$-acetylgalactosamine. Glucose oxidase and galactosamine estimations of a complete hydrolysate of compound $A_{1}$ showed these sugars to be present in equimolar concentrations. However, when the substance was first reduced with sodium borohydride and then hydrolysed, the glucose content remained 
unchanged, whereas the galactosamine content became negligible. From this it was inferred that compound $\mathrm{A}_{1}$ is a disaccharide with $\mathrm{N}$-acetylgalactosamine on its reducing end. Assuming that glucose and $N$-acetylgalactosamine are both in the D-configuration, the most probable structure of compound $A_{1}$ is 3-0- $\beta$-D-glucopyranosyl- $N$-acetyl-D-galactosamine (Fig. 2).

Glucose was not released from compound $\mathbf{A}_{1}$ by $\beta$-glucosidase, whereas the same enzyme solution showed the expected activity towards gentiobiose and cellobiose.

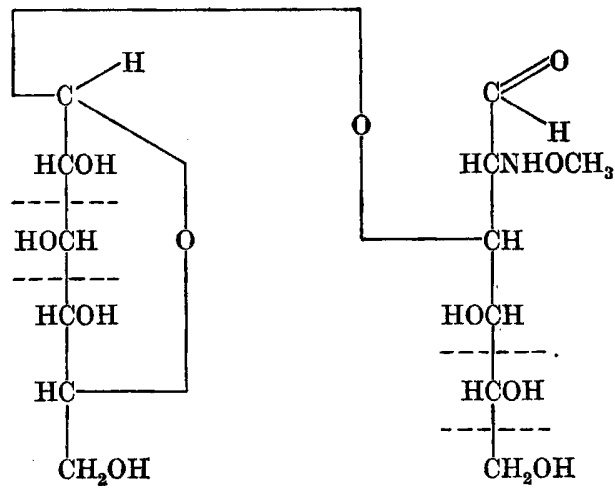

Fig. 2. 3-0- $\beta$-D-glucopyranosyl- $N$-acetyl-D-galactosamine (compound $A_{1}$ ) isolated from a partial hydrolysate of group $F$ polysaccharide. The dotted lines indicate the diol linkages which are broken on periodate oxidation (theoretical 4, found 4.2). On breakage of these linkages, formic acid (theoretical 2 , found $1 \cdot 7$ ) is formed and formaldehyde (theoretical 1 , found 0.9 ) is released.

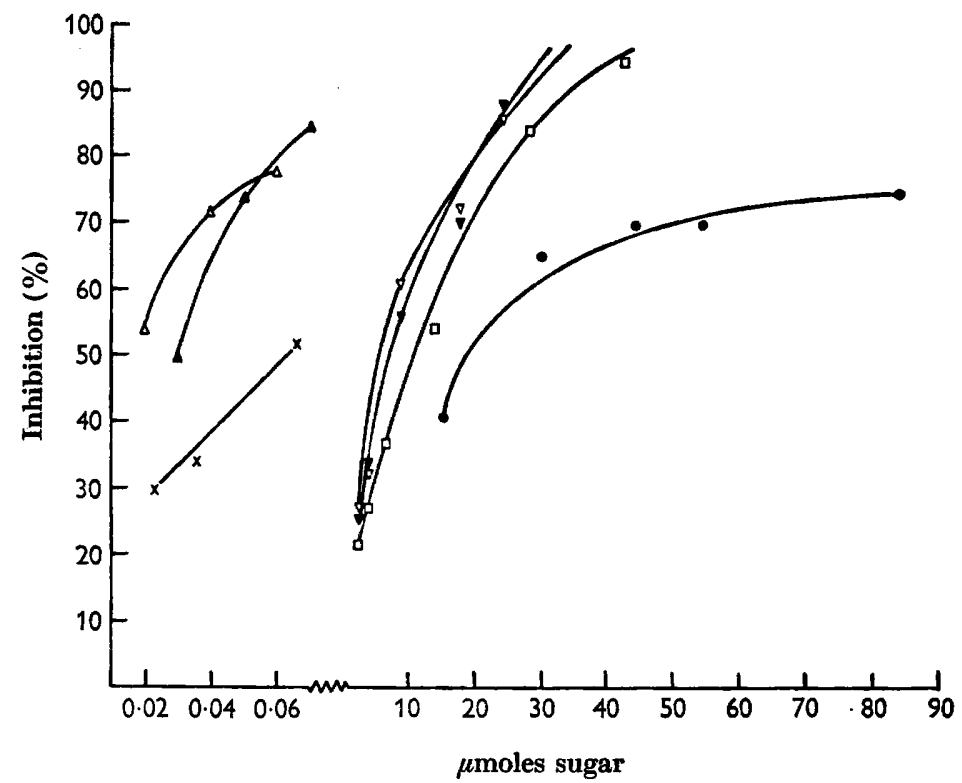

Fig. 3. Inhibitions of antigen-antibody reaction of the group $F$ system by simple sugars and oligosaccharides isolated from the $\mathbf{F}$ antigen by partial hydrolysis glucose, $\square-\square \beta$-methylglucoside, $\nabla-\nabla$ gentiobiose, $\nabla-\nabla$ cellobiose, $x-\times$ compound $A_{2}, \Delta-\Delta$ compound $A_{1}, \triangle-\triangle$ compound $A_{3}$. 
Some characteristics of compound $\boldsymbol{A}_{2}$ and $\boldsymbol{A}_{3}$. Complete hydrolysis of compound $\mathbf{A}_{2}$ yielded glucose, galactosamine and rhamnose. Compound $\mathbf{A}_{3}$ on complete hydrolysis gave glucose, galactosamine and $N$-acetylgalactosamine. Estimation of glucose and galactosamine in a complete hydrolysate showed that these sugars were present in equimolar amounts. After reduction of the substance with sodium borohydride and subsequent hydrolysis the glucose content remained unchanged. whereas the galactosamine content was halved. This suggested a tetrasaccharide. On partial hydrolysis $\left(\mathrm{N}-\mathrm{H}_{2} \mathrm{SO}_{4}\right.$ for $1 \mathrm{hr}$ ) compound $\mathrm{A}_{3}$ yielded glucose, galactosamine, compound $\mathbf{A}$ and compound $\mathbf{A}_{1}$. An additional unknown spot (galactosaminyl-glucose?) was observed but not analysed further. From these data it is suggested that compound $\mathbf{A}_{3}$ is a tetrasaccharide consisting of two molecules of $\mathbf{A}_{1}$ in series. No information is yet available about the linkage between the two disaccharides.

Serological activity of the oligosaccharides. The inhibitory effect of the oligosaccharides isolated from the PSS dialysis residue on the F/anti-F system is shown in Fig. 3. The $50 \%$ inhibition values of compound $A_{1}, A_{2}$ and $A_{3}$ were obtained with $0.02,0.05$ and $0.01 \mu$ mole, respectively. All were considerably more active than cellobiose, the best inhibitor among the simple sugars tested. No inhibition of the antigen/antibody reaction of any of the type antigens was obtained with compound $A_{1}$, when used in concentrations of 0.5-0.7 $\mu$ mole.

\section{DISCUSSION}

A disaccharide with the structure proposed for compound $A_{1}$ was described for the first time by Wolfrom \& Juliano (1960). The substance described by this author was obtained as the crystalline dihydrate from carboxyl-reduced chondroitin. The substance had an $\alpha_{D}^{20}+19^{\circ}$ which agrees well with the figure found for compound $A_{1}$. As far as known the substance was isolated here for the first time from an unmodified natural source. Dorfman \& Cifonelli (1958) reported that the spectra of the Elson-Morgan chromogens of the 2-,4- and 6-methyl substituents of glucosamine all showed a maximum at $530 \mathrm{~m} \mu$. The 3-methyl substituent however had a maximum at $510 \mathrm{~m} \mu$. This behaviour agrees well with the structure proposed for compound $A$, and has also been reported for muramic acid (Crumpton, 1959). The expected colour formation given by 3-,4- and 6-methyl-derivatives of $\mathrm{N}$-acetylglucosamine in the Morgan-Elson reaction are 160,3 , and $100 \%$ respectively of the colour produced by the unsubstituted hexosamine (Jeanloz \& Trémège, 1956). The $160 \%$ value found with compound $A_{1}$ also agrees well with the proposed $C_{3}$ substitution of its $\mathrm{N}$-acetylgalactosamine molecule. A final argument in favour of a $1 \rightarrow 3$ linkage of the disaccharide was the remarkable acid insensitivity of compound A, a property which is generally found in substances linked in this way.

It is believed that the inactivity of the $\beta$-glucosidase preparation used on compound $A_{1}$ does not invalidate the assumed $\beta$-linkage of the glucose molecule. This is inferred in the first place from the low value of optical rotation of the substance and in the second place from its activity in the inhibition reaction of the F/anti-F system. It was observed earlier (Willers et al. 1964) that in this system inhibition was obtained by glucose derivatives in the $\beta$-configuration, whereas $\alpha$-linked glucose derivatives remained without any effect. 
The inhibition on the F/anti-F system by compounds $\mathbf{A}_{2}, \mathbf{A}_{1}$ and $\mathbf{A}_{3}$ increased in that order. All were considerably more active than the simple sugars also shown in Fig. 3. It should be noted, however, that the inhibitory activity shown by compound $A_{3}$ is only slightly better than that of compound $\mathbf{A}_{1}$. This indicates, as has been reported in another system (Kabat, 1960), that with compound $A_{3}$ the chain length giving maximal inhibition may have been attained. It is therefore believed that the tetrasaccharide termed compound $A_{3}$ is a determinant group of the group $F$ polysaccharide. This assumption is further supported by the fact that the determinant groups of several other systems (Kabat, 1960; Schiffman, Kabat \& Thompson 1964; Uchida, Robbins \& Luria, 1963) are active in about the same concentrations as those used in this study.

As rhamnose has no inhibitory effect on the antigen/antibody reaction in group $\mathbf{F}$ streptococci, the methylpentose is believed to be situated at the reducing end of compound $\mathbf{A}_{2}$. The substance as a whole being fairly active it probably consists of rhamnose glycosidically linked to compound $\mathbf{A}_{1}$ (or $\mathbf{A}$ ). The rather high serological activity which remained after controlled hydrolysis of the group specific polysaccharide might well be explained by the presence of side chains of this type.

This is the second paper of a series on 'Immunochemistry of group F streptococci'. The authors are indebted to Professor Dr K. C. Winkler for constant advice; to Mr H. G. J. Overmars, Institute for Organic Chemistry, T.N.O., Utrecht, for the preparation of polystyrene sulphonic acid; to Miss T. Alderkamp, Miss I. Nebbeling and Mr F. Exterkate for skilful assistance.

The work has been financially supported by the Netherlands Organization for the Advancement of Pure Research (Z.W.O.).

\section{REFERENCES}

BLock, R. M. \& LiNg, N. S. (1954). Devices for gradient elution in chromatography. Anal. Chem. 26, 1543.

Consden, R. G. \& Gordon, H. (1948). Effect of salt on partition chromatograms. Nature, Lond. 162, 180.

Crumpton, M. J. (1959). Identification of amino sugars. Biochem. J. 72, 479.

Dorfman, A. \& Crfonelli, J. A. (1958). In Chemistry and Biology of Mucopolysaccharides. Ciba Foundation Symposium, ed. by C. E. W. Wolstenhome \& M. O'Connor, p. 64. London: Churchill.

Dubois, M., Gilles, K. A., Hammton, J. K., Rebers, P. A. \& Smith, F. (1956). Colorimetric method for determination of sugars and related substances. Anal. Chem. 28, 350.

Fuller, A. T. (1938). The formamide method for the extraction of polysaccharides from haemolytic streptococci. Brit. J. exp. Path. 19, 130.

Gardeld, S. (1953). Separation on Dowex 50 ion exchange resin of glucosamine and galactosamine and their quantitative determination. Acta chem. scand. 7, 207.

Gibbons, M. N. (1955). The determination of methylpentoses. Analyst, 80, 268.

Hugetr, A. St G. \& Nixon, D. A. (1957). Use of glucose oxidase, peroxidase and 0dianisidine in determination of blood and urinary glucose. Lancet, ii, $\mathbf{3 6 8 .}$

JeAnloz, R. W. \& TrÉmèGe, M. (1956). Color reaction of $\mathrm{N}$-acetyl-amino sugar derivatives with $p$-dimethylbenzaldehyde. Fed. Proc. 15, 282.

KABAT, E. A. (1960). The upper limit for the size of the human antidextran combining site. J. Immunol. 84, 82.

KABAT, E. A. \& MAYER, M. (1961). Experimental Immunochemistry. Springfield, Illinois, U.S.A.: Charles C. Thomas. 
MacFadyen, D. A. (1945). Estimation of formaldehyde in biological mixtures. J. biol. Chem. 158, 107.

Michei, M. F. \& Gooder, H. (1962). Amino acids, amino sugars and sugars present in the cell wall of some strains of Streptococcus pyogenes. J. gen. Microbiol. 29, 199.

OTtENs, H. (1961). Indifferente en haemolytische streptococcen met groepsantigeen $F$. Thesis, University of Utrecht.

OTteNs, H. \& WinkLER, K. C. (1962). Indifferent and haemolytic streptococci possessing group antigen F. J. gen. Microbiol. 28, 181.

Painter, T. J. (1960). Water soluble polystyrenesulphonic acid as a catalyst in the controlled fragmentation of very labile polysaccharides. Chem. Industr. 1214.

Painter, T. J. \& Morgan, W. T. J. (1961). Partial acid-hydrolysis of a mucopolysaccharide without appreciable $N$-deacetylation of hexosamine. Nature, Lond. 191, 39.

Partridge, S. M. (1948). Filter-paper chromatography of sugars. Biochem. J. 42, 238.

Perlin, A. S. (1954). Oxidation of carbohydrate with periodate in the Warburg respirometer. J. Am. chem. Soc. 76, 4101.

Reissig, J. L., Strominger, J. L. \& Leloir, L. F. (1956). A modified colorimetric method for the estimation of $N$-acetylamino sugars. J. biol. Chem. $217,959$.

Rondle, C. I. M. \& Morgan, W. T. J. (1955). The determination of glucosamine and galactosamine. Biochem. J. 61, 586.

Salton, M. R. J. (1959). An improved method for the detection of $\boldsymbol{N}$-acetylamino sugars on paper chromatograms. Biochim. biophys. Acta, 34, 308.

Schiffman, G., Howe, C. \& Kabat, E. A. (1958). Immunochemical studies on blood groups. XVI. Chromatographic examination of constituents split from blood group A, $B$, and $O(H)$ substances and from type XIV pneumococcal polysaccharide by Clostridium tertium enzymes. J. Am. chem. Soc. 80, 6662.

Schiffman, G., Kabat, E. A. \& Thompson, W. (1964). Immunochemical studies on blood groups. XXX. Cleavage of $\mathrm{A}, \mathrm{B}$, and $\mathrm{H}$ blood-group substances by alkali. Biochemistry, N.Y. 3, 113.

Trevelyan, W. E., Proctor, D. P. \& Harrison, I. S. (1950). Detection of sugars on paper chromatograms. Nature, Lond. 166, 444.

Uchida, T., Robbins, P. W. \& Luria, S. E. (1963). Analysis of the serologic determinant groups of the Salmonella E-group O-antigens. Biochemistry, 2, 663.

Willers, J. M. N., Michel, M. F., SiJsma, M. J. \& Winkler, K. C. (1964). Chemical analysis and inhibition reactions of group and type antigens of group $\mathrm{F}$ streptococci. J. gen. Microbiol. 36, 95.

Wolfrom, M. R. \& Juliano, B. O. (1960). Chondroitin sulfate modifications. I. Carboxylreduced chondroitin and chondrosine. J. Am. chem. Soc. 82, 1673. 